\title{
Another Reason for Impeccable Oral Hygiene: Oral Hygiene-Sperm Count Link
}

\author{
${ }^{1}$ Solomon Olusegun Nwhator, ${ }^{2}$ Kehinde A Umeizudike, ${ }^{3}$ Patricia 0 Ayanbadejo, ${ }^{4}$ Olanrewaju I Opeodu \\ ${ }^{5}$ Joseph A Olamijulo, ${ }^{6}$ Timo Sorsa
}

\section{ABSTRACT}

\section{Objectives:}

1. To investigate the relationship between periodontitis and infertility.

2. To evaluate the importance of oral hygiene to general health.

Materials and methods: Eighty-six men requiring seminal fluid analysis as part of an on-going investigation for infertility in their spouses were serially recruited into the study. Basic dental and periodontal examination were performed. Each participant was also screened for periodontitis using a lateral flow immunoassay kit which detected levels of active membrane metalloproteinase-8. Results were read-off as a color change. Due to some incomplete entries, only 76 participants were involved in the final data analysis.

Results: There were 55 subjects with subnormal counts (of which ten were found to be azoospermic, 41 oligospermic) and 25 normospermic controls. A positive association was found between periodontitis and subnormal sperm count in only one age group but statistically significant association was found between poor oral hygiene and subnormal sperm count across all age groups.

Conclusion: For the first time, there appears to be a significant association between poor oral and subnormal sperm count. There also appears to an association between chronic periodontitis and subnormal sperm count. These relationships warrant further investigation.

\footnotetext{
${ }^{1}$ Senior Consultant, ${ }^{2,4}$ Lecturer and Consultant, ${ }^{3}$ Senior Lecturer and Consultant, ${ }^{5}$ Lecturer, ${ }^{6}$ Professor and Chief Physician

${ }^{1}$ Department of Preventive Dentistry, University of Abuja Teaching Hospital, Abuja, Nigeria

${ }^{2,3}$ Department of Preventive Dentistry, University of Lagos Lagos, Nigeria

${ }^{4}$ Department of Periodontology and Community Dentistry University of Ibadan, Oyo, Nigeria

${ }^{5}$ Department of Obstetrics and Gynecology, University of Lagos, Lagos, Nigeria

${ }^{6}$ Department of Oral and Maxillofacial Diseases, University of Helsinki, Helsinki
}

Corresponding Author: Solomon Olusegun Nwhator Senior Consultant, Department of Preventive Dentistry University of Abuja Teaching Hospital, Abuja, Nigeria, Phone: +2348093690829, e-mail: periodontologist2010@gmail.com
Principal findings: There appears to be a link between poor oral hygiene and low sperm count.

Keywords: Poor oral hygiene, Low sperm count, Nigeria.

How to cite this article: Nwhator SO, Umeizudike KA, Ayanbadejo PO, Opeodu OI, Olamijulo JA, Sorsa T. Another Reason for Impeccable Oral Hygiene: Oral Hygiene-Sperm Count Link. J Contemp Dent Pract 2014;15(3):352-358.

Source of support: Nil

Conflict of interest: None declared

\section{PRACTICAL IMPLICATIONS FOR GENERAL DENTAL PRACTICE}

Infertility is such a stressful condition, hence, every bit of evidence ought to be investigated. If the association uncovered in the present study is sufficiently corroborated by future studies, urgent public enlightenment efforts need to be made to correct this simple problem.

Dentists and hygienists often face an uphill task convincing men to maintain good oral hygiene. It is possible that men are not really aware of the social implications of poor oral hygiene apart from embarrassment from halitosis and an unsightly smile.

Should a link between poor oral hygiene and I infertility problems be established, the general dental practitioner and the hygienist will become armed with another tool—a strong one-which could finally gain the attention of men to attend to their oral hygiene.

\section{BACKGROUND}

Oral hygiene has always been encouraged for the purpose of good oral health and its attendant social benefits. These benefits have in recent years been extended to general health in aspects previously considered inconsequential to oral health. More lately, one of these general health aspects that is attracting attention happens to be fertility. This gives the oral health practitioner another reason to encourage excellent oral hygiene practices especially among men - often guilty of oral hygiene neglect!

Infertility is defined as the inability of a couple to have children despite 12 months of regular, unprotected sexual intercourse. ${ }^{12}$ The World Health Organization recognizes infertility as a global problem with estimates ranging between 
8 and $12 \%$ among couples with women of childbearing age. ${ }^{2}$ The burden however appears higher in developing countries with an estimated one in three couples affected in central Africa $^{3}$ while Adetoro and Ebomoyi in a community-based Nigerian study reported a prevalence of $30 \%{ }^{4}$

Infertility constitutes a crisis in affected African families bringing extreme emotional and psychological distress to couples desiring to raise a family. As the traditional African myth of blaming wives for their inability to conceive are fast giving way to evidence-based scientific views, it behooves the scientific community to continuously research every bit of evidence on potential real causes of infertility. This might help to minimize stigmatization as well as the mental, emotional and psychological stress being experienced by infertile couples particularly in Africa where these misconceptions are endemic. ${ }^{5}$

The last two decades have witnessed an unprecedented wave of scientific research into periodontitis and systemic health in support of a two-way relationship between the mouth and the rest of the body. Expectedly, results of such investigations have ranged from cautious optimism to outright rejection in some quarters, but evidence continues to build in support of a possible link between chronic periodontitis and systemic health.

One of such possible links currently being explored is that between chronic periodontitis and infertility. As absurd and novel as this may sound, historical evidence in literature supports a faint pointer to this link. From the focal infection theory of $1909^{6}$ to Berger's focal allergy theory of $1939^{7}$ and Slauk's focal toxicosis theory of the $1940 \mathrm{~s}^{8,9}$ we cannot truthfully say that the phenomenon is entirely new.

Bieniek and Riedel ${ }^{10}$ in 1986 reported that spermiograms from subjects suffering from antibiotic-resistant bacteriospermia became sterile after identifying and eliminating possible 'oral foci' of infection. Remarkably, the subjects' intraoral bacterial spectrum and the spermiograms were identical, fuelling their conclusion of 'a direct causal relationship between dental primary diseases and asymptomatic bacteriosperms'. Their work ought to be properly credited as one of the most remarkable in reawakening interest in this unusual relationship.

Periodontal infection-induced cytokines toxins and proteolytic enzymes destroy the surrounding gingival tissue and cause persistent and silent systemic inflammation. This is reflected by elevation and activation of collagenolytic MMP-8 (aMMP-8) in oral fluids such as mouthrinse, and recently oral fluid point-of-care aMMP-8 diagnostics tools have been developed. ${ }^{11}$

It is noteworthy though, that their work was probably inspired by a previous $1982^{12}$ report of the isolation of a possible 'sperm immobilizing factor' from necrotic dental pulp E. coli by Linossier et al, yet all these pieces of evidence were left univestigated for another two decades!

Finally, in 2011 the possible link between periodontitis and fertility was revisited in a report by Kligner et $\mathrm{al}^{13}$ of an association between chronic periodontitis and sperm submotility. Their work kindled our interest and informed the decision to replicate this study in Nigeria.

\section{MATERIALS AND METHODS}

\section{Ethical Clearance}

All aspects of the research were performed in full accordance with the World Medical Association Declaration of Helsinki and were approved by the research and ethics committees of the participating hospitals namely, the Lagos University Teaching Hospital (LUTH) and the University College Hospital (UCH), Ibadan, South-West Nigeria. Informed consent was obtained from study participants and personal details were treated with utmost respect and confidentiality.

\section{Study Setting}

Teaching Hospitals in South-West Nigeria.

\section{Subjects and Controls}

All participants were patients undergoing seminal fluid analysis (SFA) investigating sperm parameters including count and motility. Normal sperm count was taken as values of $\geq 20 \times 10^{6}$ per $\mathrm{ml}$ and normal motility as $\geq 25 \%$. ${ }^{14}$

\section{Sampling}

Non-random, serial recruitment. Initially 86 men but trimmed down to 76 after data cleaning to eliminate incomplete entries. Followed pattern of and compares with the 75 subjects seen in the study that was replicated.

\section{Material and Research Instrument}

Examiner (interviewer) administered questionnaires were used to obtain demographic and other participant-specific details while the main material and research instrument was the oral risk indicator kit which measures mouthrinse levels of the active matrix metalloproteinase- 8 (aMMP-8) ${ }^{15}$ was used per participant to evaluate presence or absence of periodontitis risk even ahead of clinical signs and symptoms of the disease. The results are read-off as a color change. An aMMP-8 oral risk Indicator is an effective point-of-care indicator or biomarker of existing and previously concealed or hidden periodontal inflammations/infections in potential risk groups. ${ }^{11,16,17}$

After giving specific rinsing instructions as specified by the manufacturer, the mouth rinse was filtered into a reading 
dish which displayed a control in all valid tests and a test line only in participants with increased risk of chronic periodontitis.

\section{Periodontal Evaluation}

The oral hygiene of participants was evaluated and recorded using the simplified oral hygiene index of greene and vermillion (1960) with sums of oral hygiene index scores of 0 to 1.2 recorded as 'Good', 1.3 to 3.0 as 'Fair' and 3.1 to 6.0 recorded as 'Poor'. ${ }^{18}$

Basic periodontal examination was performed using the CPITN probe. ${ }^{19}$ Parameters in each sextant were entered using recognized codes from 0 to 4 .

\section{Data Analysis and Statistics}

Data were cleaned and presented in the form of tables and charts. Analyses were performed using the PASW statistical software (SPSS) version $18 .{ }^{20}$

The outcome (dependent) variables were sperm count and sperm motility while the explanatory (independent) variables included presence or absence of periodontitis risk measured by results of the oral risk indicator kit, ${ }^{11,17}$ debris index score, calculus index score, Community periodontal index of treatment need (CPITN) individual sextant score, CPITN max scores (highest score of six examined sextants), age group, bleeding on gentle probing.

Univariate analyses for frequencies and standard deviations of recorded parameters were performed. Cross-tabulations and Chi-square statistics were used to measure strength of association between the outcome and explanatory variables with all cross-tabulations of expected cells greater $25 \%$ were regarded as invalid and alternative means of test of association employed.

Adjunctive statistical analysis was performed using t-test (Epi-Info) $)^{21}$ to evaluate the association between two continuous variables and ANOVA used to evaluate associations between the means of three or more dependent variables, such as azoospermia, oligospermia and normospermia against independent variables like oral hygiene index score (OHIS). Z-test statistics were performed to evaluate associations between percentages.

Since, the study was carried at $95 \%$ confidence level, analyses yielding $p$-values of $\leq 0.05$ were considered statistically significant.

All participants were Nigerians to eliminate confounders of race in sperm count and motility. All the participants were married, hence marital status was eliminated from the analyses.

Subjects and controls were also matched for age in all instances of comparisons of associations for statistical signi- ficance to eliminate age as a confounder for sperm count and motility. Age groupings for the purpose of matching into $27-32,33-38,39-44$ and $\geq 45$ years was completely arbitrary and for convenience of analyses.

Statistical analyses were performed between subjects and controls across two categories in most instances. Category one involved considering participants under azoospermia, oligospermia and normospermia while category two involved just two subclasses-subnormal count and normospermia. In category two, all cases of azoospermia and oligospermia were grouped as 'subnormal' count.

All examiners were under the guidance and supervision of a consultant periodontologist. They were judged competent to perform the various evaluations and measurements in order to reduce interexaminer variability to the barest minimum. The total sample size after data cleaning was 76 (51 subnormal count subjects and 25 normal count controls).

\section{RESULTS}

\section{Age Distribution}

Of the total number of 76 participants with ages ranging between 27 and 56 years, 10 were found to be azoospermic, 41 oligospermic and 25 normospermic culminating in a distribution of 51 subnormal count subjects and 25 normospermic controls (Table 1).

\section{CPITN Max Scores}

There was no significant difference between percentage CPITN Max scores of subjects and controls $(p>0.05)$, (z-values as shown below Table 2).

\section{Sextant Analyses}

Analyses of sextants demonstrated no statistically significant difference between mean number of healthy sextants (Code 0 ) among age-matched subjects and controls $(p>0.05)$. There were also no significant differences in mean number of Code 1 (gingival bleeding) sextants and sextants with calculus (Code 2) $(\mathrm{p}>0.05)($ Table 3).

\section{Periodontal Pocket}

There was a significant association between periodontitis (periodontal pocket) and subnormal sperm counts $[0.02599$ $(\mathrm{CI}=0.141089-2.03891)]$ among subjects and controls within the 33 to 38 years age group only. There was also a slight association $(p=0.08219)$ between subnormal sperm counts and having periodontal pocket (Code 3 ) demonstrated from a sextant analysis of cumulative Code 0-3 scores among subjects and controls (Table 4). 
Another Reason for Impeccable Oral Hygiene: Oral Hygiene-Sperm Count Link

Table 1: Age distribution of participants

\begin{tabular}{|c|c|c|c|c|c|c|}
\hline \multirow{2}{*}{$\begin{array}{l}\text { Age groups } \\
\text { Years }\end{array}$} & \multicolumn{2}{|c|}{ Subnormal } & & & \multicolumn{2}{|c|}{ Normal } \\
\hline & $n$ & $\%$ & & & $n$ & $\%$ \\
\hline $27-32$ & 7 & 58.3 & & & 5 & 41.7 \\
\hline $33-38$ & 19 & 67.9 & & & 9 & 32.1 \\
\hline $39-44$ & 16 & 72.3 & & & 6 & 27.3 \\
\hline$>45$ & 9 & 64.3 & & & 5 & 35.7 \\
\hline \multirow[t]{2}{*}{ Total } & 51 & 67.1 & & & 25 & 32.9 \\
\hline & \multicolumn{2}{|c|}{ Azoosperm } & \multicolumn{2}{|c|}{ Oligosperm } & \multicolumn{2}{|c|}{ Normosperm } \\
\hline $27-32$ & 1 & 8.3 & 6 & 50 & 5 & 41.7 \\
\hline $33-38$ & 5 & 17.9 & 14 & 50 & 9 & 32.1 \\
\hline $39-44$ & 3 & 13.6 & 13 & 59.1 & 6 & 27.3 \\
\hline$>45$ & 1 & 7.2 & 8 & 57.1 & 5 & 35.7 \\
\hline Total & 10 & 13.2 & 41 & 53.9 & 25 & 32.9 \\
\hline
\end{tabular}

Table 2: CPITN Max scores of subjects and controls

\begin{tabular}{|c|c|c|c|c|c|c|c|c|}
\hline \multirow{3}{*}{$\begin{array}{l}\text { Age group } \\
\text { Sperm count } \\
\text { \% with CPITN Max } 0\end{array}$} & \multirow{2}{*}{\multicolumn{2}{|c|}{$\begin{array}{c}27 \text { to } 32 \\
\begin{array}{c}\text { Normal/Subnormal } \\
(n=5) /(n=7)\end{array}\end{array}$}} & \multirow{2}{*}{\multicolumn{2}{|c|}{$\begin{array}{c}33 \text { to } 38 \\
\begin{array}{c}\text { Normal/Subnormal } \\
(n=9) /(n=19)\end{array}\end{array}$}} & \multirow{2}{*}{\multicolumn{2}{|c|}{$\begin{array}{c}39 \text { to } 44 \\
\begin{array}{c}\text { Normal/Subnormal } \\
(n=6) /(n=16)\end{array}\end{array}$}} & \multirow{2}{*}{\multicolumn{2}{|c|}{$\begin{array}{l}\geq 45 \\
\text { Normal/Subnormal } \\
\quad(n=5) /(n=9)\end{array}$}} \\
\hline & & & & & & & & \\
\hline & 20 & $0^{\mathrm{a}}$ & 0 & 0 & 0 & $6.3^{\mathrm{b}}$ & 0 & 0 \\
\hline \% with CPITN Max 1 & 0 & 0 & 0 & 0 & 0 & $6.3^{b}$ & 0 & 0 \\
\hline$\%$ with CPITN Max 2 & 60 & $42.9^{c}$ & 66.7 & $42.1^{\mathrm{e}}$ & 33.3 & $43.8^{9}$ & 80 & $66.7^{i}$ \\
\hline \% with CPITN Max 3 & 20 & $28.6^{d}$ & 33.3 & $57.9^{f}$ & 50 & $37.5^{\mathrm{h}}$ & 0 & $22.2^{\mathrm{j}}$ \\
\hline
\end{tabular}

Z-statistic: $a=1.236 ; b=0.629 ; c=0.584 ; d=0.339 ; e=1.216 ; f=1.216 ; g=0.446 ; h=0.531 ; i=0.528 ; j=0.138$

Table 3: CPITN sextant analysis: sextant code scores 0,1 and 2

\begin{tabular}{|c|c|c|c|c|c|c|}
\hline \multirow{2}{*}{$\begin{array}{l}\text { Age groups } \\
\text { (Years) }\end{array}$} & \multicolumn{2}{|c|}{ Subnormal } & \multicolumn{2}{|c|}{ Normal } & \multirow[t]{2}{*}{$d f$} & \multirow[t]{2}{*}{$p$-value } \\
\hline & Mean & $S D$ & Mean & $S D$ & & \\
\hline $27-32$ & 1.14 & 1.21 & 2.20 & 2.28 & 10 & 0.317 \\
\hline $33-38$ & 0.89 & 1.29 & 1 & 1.58 & 26 & 0.846 \\
\hline $39-44$ & 1 & 1.55 & 1.83 & 1.94 & 20 & 0.308 \\
\hline$\geq 45$ & 0.78 & 0.83 & 0.40 & 0.89 & 12 & 0.439 \\
\hline \multicolumn{7}{|c|}{ Mean number of Code 1 (Bleeding) sextants among subjects and controls (Independent t-test) } \\
\hline $27-32$ & 0.86 & 1.21 & 0.40 & 0.89 & 10 & 0.489 \\
\hline $33-38$ & 0.42 & 0.9 & 0.33 & 0.71 & 26 & 0.795 \\
\hline $39-44$ & 1 & 1.55 & 0.17 & 0.41 & 20 & 0.216 \\
\hline$\geq 45$ & 0.67 & 1.32 & 1.4 & 2.19 & 6 & 0.522 \\
\hline \multicolumn{7}{|c|}{ Mean number of Code 2 (Calculus) sextants among subjects and controls (Independent t-test) } \\
\hline 27-32 & 2.86 & 1.35 & 3.2 & 1.92 & 10 & 0.725 \\
\hline 33-38 & 3.5 & 1.29 & 4.11 & 1.54 & 26 & 0.701 \\
\hline $39-44$ & 2.69 & 1.92 & 2.33 & 1.97 & 20 & 0.216 \\
\hline$\geq 45$ & 3.78 & 1.09 & 3.6 & 2.07 & 12 & 0.832 \\
\hline
\end{tabular}

\section{Oral Hygiene}

There were no significant differences between oral hygiene scores among subjects and controls $(p>0.05)$ but there was a significant association between poor oral hygiene and subnormal sperm count $(\mathrm{p}=0.048)$ (Table 5).

\section{DISCUSSION}

Kligner et $\mathrm{al}^{13}$ reopened research efforts into an unexpected yet possible association between oral health and reproductive health. The link they found between periodontitis and infertility was directly related to a positive correlation between chronic periodontitis and sperm submotility. Being a strong indicator of male fertility, adequate progressive motility is considered important in the fertilization process. ${ }^{22}$ A previous report ${ }^{7}$ of isolation of a 'sperm immobilizing factor' from $E$. coli isolated from necrotic dental pulp appears, to at least in part, explain the link between chronic periodontitis and sperm submotility.

The mediating role of tumor necrosis factor (TNF)-alpha in systemic diseases associated with periodontitis ${ }^{23-25}$ is well documented as well as the interesting effect of anti-TNF therapy in treatment of sufferers of rheumatic diseases. Investigations of possible adverse effects of anti-TNF the- 
Table 4: Association between periodontal pockets and subnormal sperm count

\begin{tabular}{|c|c|c|c|c|c|c|}
\hline \multirow{2}{*}{$\begin{array}{l}\text { Age groups } \\
\text { (Years) }\end{array}$} & \multicolumn{2}{|c|}{ Subnormal } & \multicolumn{2}{|c|}{ Normal } & \multirow[t]{2}{*}{$d f$} & \multirow[t]{2}{*}{$p$-value } \\
\hline & Mean & $S D$ & Mean & $S D$ & & \\
\hline $27-32$ & 1.14 & 1.35 & 0.20 & 0.45 & 10 & 0.169 \\
\hline $33-38$ & 1.53 & 1.71 & 0.44 & 0.73 & 26 & $0.026(\mathrm{Cl}=0.141-2.039)$ \\
\hline $39-44$ & 0.94 & 1.34 & 1.33 & 1.51 & 20 & 0.563 \\
\hline$>45$ & 0.56 & 1.33 & 0.4 & 0.89 & 12 & 0.815 \\
\hline \multicolumn{7}{|c|}{ Mean number of sextants among subjects and controls (Independent t-test) } \\
\hline Code 0 & 0.96 & 1.28 & 1.32 & 1.75 & 74 & 0.312 \\
\hline Code 1 & 0.84 & 1.3 & 0.52 & 1.16 & 74 & 0.3 \\
\hline Code 2 & 3.2 & 1.53 & 3.4 & 1.85 & 74 & 0.619 \\
\hline Code 3 & 1.11 & 1.49 & 0.6 & 1 & 67 & 0.082 \\
\hline
\end{tabular}

Table 5: Association between poor oral hygiene and subnormal sperm count

\begin{tabular}{|c|c|c|c|c|c|c|}
\hline \multicolumn{7}{|c|}{ Mean oral hygiene index score (OHIS) among subjects and controls (Independent t-test) } \\
\hline \multirow{2}{*}{$\begin{array}{l}\text { Age groups } \\
\text { (Years) }\end{array}$} & \multicolumn{2}{|c|}{ Subnormal } & \multicolumn{2}{|c|}{ Normal } & \multirow[t]{2}{*}{$d f$} & \multirow[t]{2}{*}{ p-value } \\
\hline & Mean & $S D$ & Mean & $S D$ & & \\
\hline $27-32$ & 3.07 & 1.68 & 1.67 & 0.96 & 10 & 0.127 \\
\hline $33-38$ & 2.65 & 1.11 & 2.19 & 1 & 26 & 0.301 \\
\hline $39-44$ & 2.51 & 1.41 & 1.64 & 0.9 & 20 & 0.178 \\
\hline$>45$ & 2.8 & 1.14 & 1.8 & 1.01 & 12 & 0.129 \\
\hline \multicolumn{7}{|c|}{ Oral hygiene status of subjects and controls } \\
\hline & \multicolumn{3}{|c|}{ Normal } & \multicolumn{2}{|c|}{ Subnormal } & Total \\
\hline \multicolumn{2}{|l|}{ Good oral hygiene } & \multicolumn{2}{|l|}{7} & \multicolumn{2}{|c|}{6} & 13 \\
\hline \multicolumn{2}{|l|}{ Fair oral hygiene } & \multicolumn{2}{|l|}{14} & \multicolumn{2}{|l|}{24} & 38 \\
\hline \multicolumn{2}{|l|}{ Poor oral hygiene } & \multicolumn{2}{|l|}{4} & \multicolumn{2}{|l|}{21} & 25 \\
\hline \multicolumn{2}{|l|}{ Total } & \multicolumn{2}{|l|}{25} & \multicolumn{2}{|l|}{51} & 76 \\
\hline \multicolumn{2}{|l|}{ Pearson Chi-square } & \multicolumn{2}{|l|}{$\chi^{2}=6.086 a$} & \multicolumn{2}{|c|}{$\mathrm{df}=2$} & $p=0.048$ \\
\hline \multicolumn{2}{|l|}{ Likelihood ratio } & \multicolumn{2}{|l|}{$\chi^{2}=6.337$} & \multicolumn{2}{|c|}{$\mathrm{df}=2$} & $p=0.042$ \\
\hline
\end{tabular}

rapy on sperm motility demonstrated the contrary-improved sperm motility. ${ }^{26-28}$ Could elevated levels of TNF-alpha reflecting persistent systemic inflammation in chronic periodontitis be the link between chronic periodontitis and reduced sperm submotility?

Had we found a link between chronic periodontitis and submotility, our study could have enjoyed the same simple explanation. Unfortunately, the explanations are not that simple for our study, because we found no association between chronic periodontitis and sperm submotility. The failure to demonstrate this association however most likely lies in subtle differences in methodology. While Kligner et $\mathrm{al}^{13}$ evaluated clinical attachment loss which is the true measure of periodontal status, our study employed the use of a sensitive oral risk indicator which 'picks' chronic periodontitis even ahead of overt periodontal destruction. The oral fluid point-of-care aMMP-8 test can reveal oral periodontal destructive and related systemic inflammation caused by collagenase aMMP-8. Thus, the test can identify the risk even before any clinical signs become visible/detectable. ${ }^{11}$

Analysis of CPITN sextants used in our study attempts to overcome the loss of details occasioned by recording only the worst score per sextant and has been so used in literature. ${ }^{29}$ Sextant analyses in our study failed to demonstrate any association between chronic periodontitis and subnormal count and submotility for Codes 0 to 2 . This probably indicates that other factors rather than chronic periodontitis were responsible for subnormal sperm parameters in patients not suffering from periodontitis. However, the possible link shows up with analysis of Code 3 sextants which was statistically significant $(p<0.05)$ corroborating a previous report. ${ }^{13}$

For the first time, we demonstrated an association between oral hygiene and sperm count-an association between poor oral hygiene and oligospermia and azoospermia when considered together as subnormal sperm count. Now, herein lies the difficulty in our findings; while plausible explanations exist for the association between chronic periodontitis and sperm submotility the link with oligospermia is not that easily explained.

The difficulty in explanation does not, however, wish away this strong association with 21 of 25 subjects (84\%) with poor oral hygiene shown to suffer from subnormal sperm counts. Based on this finding, we therefore propose two possible hypotheses for the link between poor oral hygiene and low sperm count.

One possible link is between poor oral hygiene and chronic periodontitis through elevated TNF-alpha levelsthis however does not explain reduced counts except TNF 
can cause testicular dysfunction. TNF-alpha has been shown to be associated with varicocele-induced testicular dysfunction with consequent apoptosis and low perm count through the TNF-related apoptosis-inducing ligand (TRAIL). ${ }^{30}$

A more plausible link might lie in the similarity between oral microflora and microbials in spermiograms, as demonstrated in a previous report. ${ }^{10}$

Poor oral hygiene and related increased bacterial load might translate into bacteriospermia in the subjects. Recent reports have demonstrated the ability of certain oral organisms like Fusobacterium nucleatum together with aMMP-8 to act as 'gate openers' for other periodontopathic organisms to gain access into the systemic circulation. ${ }^{16,31}$ The workers demonstrated the inability of organisms like $E$. coli to penetrate the endothelium into the systemic circulation in the absence of $F$. nucleatum. This means that the documented spermatozoa inhibitory factor expressed by $E$. coli ${ }^{32,33}$ would have no effect without the help of $F$. nucleatum.

It would therefore be appropriate for future studies to evaluate TNF-alpha and aMMP-8 levels in subjects and controls as well as perform $F$. nucleatum and $E$. coli counts in the mouths of subfertile males to explore these possible links.

\section{CONCLUSION}

There appears to be an association between poor oral hygiene and subnormal sperm count. With the multifaceted nature of the etiology of infertility and sperm count, the authors do not claim that every case of low sperm count would be resolved by improved oral hygiene. All we have attempted to highlight is that impeccable oral hygiene would at least remove one of the several variables that could be related to infertility as a result of low sperm count. It is important to note however, that the mechanisms for this association need to be further investigated.

\section{LIMITATIONS}

While the use of CPI in this study appears to be a limitation, analysis of sextants obviously overcomes this limitation. Furthermore, the use of an oral fluid point-of-care aMMP8 test overcomes any other deficiencies of the CPITN with a reported (34) 96\% sensitive for poor oral hygiene, 95\% sensitive for chronic periodontitis and $82.6 \%$ sensitivity for bleeding on probing.

\section{REFERENCES}

1. De Melo-Martin I. On cloning human beings. Bioethics 2002; 16(3):246-265.

2. World Health Organization. 1991. Infertility: a tabulation of available data on prevalence of primary and secondary infertility. WHO: Geneva. Programme on Maternal and Child Health and Family Planning, Division of Family Health.
3. Inhorn MC. Global infertility and the globalization of new reproductive technologies: illustrations from Egypt. Soc Sci Med 2003; 56(9):1837-1851.

4. Adetoro OO, Ebomoyi EW. The prevalence of infertility in a rural Nigerian community. African J Medici Med Sci 1991; 20(1):23-27.

5. Umeora OJ, Igberase G, Okogbenin S, Obu I. Cultural misconceptions and emotional burden of infertility in South East Nigeria. Int J Gynecol Obstet 2008;10(2).

6. Easlick KA. An evaluation of the effect of dental foci of infection on health. J Am Dent Assoc 1951 Jun;42(6):615-697.

7. Berger W. Die fokale Infektion als Problem der Allergie. Verh Dtsch Ges Inn Med 56 Wiesbaden, Bergmann, Leipzig 1939.

8. Slauk A. Plaque disease and dentist. Publisher Gehlen, Leipzig. (Article in German) 1940.

9. Slauk A. From the nature of focal disease: Fokalinfekt and Fokaltoxikose. Publisher Gehlen, Leipzig 1944.

10. Biennia KW, Riedel HH. Bacterial foci in the teeth, oral cavity, and jaw-secondary effects (remote action) of bacterial colonies with respect to bacteriospermia and subfertility in males. Andrologia 1993;25(3):159-162.

11. Sorsa T, Tervahartiala T, Leppilahti J, Hernandez M, Gamonal J, Tuomainen AM, Lauhio A, Pussinen PJ, Mäntylä P. Collagenase-2 (MMP-8) as a point-of-care biomarker in periodontitis and cardiovascular diseases. Therapeutic response to non-antimicrobial properties of tetracyclines. Pharmacol Res 2011;63(2):108-113.

12. Linossier A, Thumann A, Bustos-Obregon E. Sperm immobilization by dental focus microorganisms. Andrologia 1982; $14(3): 250-255$.

13. Klinger A, Hain B, Yaffe H, Schonberger O. Periodontal status of males attending an in vitro fertilization clinic. J Clin Periodontol 2011 Jan;38(6):542-546.

14. World Health Organization. WHO laboratory manual for the examination of human semen and sperm-cervical mucus interaction. 4th ed. Cambridge, UK: Cambridge University Press 1999.

15. PerioMarker aMMP-8 Rapid Test. A lateral flow immunoassay for the examination of mouth-rinse samples. Manufactured by dentognostics and sold to Hager and Werken.

16. Sorsa T, Hernández M, Leppilahti J, Munjal S, Netuschil L, Mäntylä P. Detection of gingival crevicular fluid MMP-8 levels with different laboratory and chair-side methods. Oral Dis 2010; 16(1):39-45.

17. Sorsa T, Tjäderhane L, Salo T. Matrix metalloproteinases (MMPs) in oral diseases. Oral Dis 2004;10(6):311-318.

18. Greene JC, Vermillion JR. Oral Hygiene index: a method for classifying oral hygiene status. JADA 1960;61(2):172-178.

19. Ainamo J, Barnes D, Beagrie, Cutress T, Martin J, Sardo-Infini J. Development of the World Health Organisation (WHO) Community Periodontal Index of Treatment Needs (CPITN). Int Dent J 1982;32:281-301.

20. PASW (SPSS) Statistics 18, Release 18.0.0 (July 30, 2009).

21. Epi. Info-version 7: a word processing database and statistics programme for public health on IBM-compatible microcomputer. Centre for disease control and prevention, Atlanta Georgia USA 2011.

22. Prabha V, Gupta T, Kaur S, Kaur N, Kala S, Singh A. Isolation of a spermatozoal immobilization factor from Staphylococcus aureus filtrates. Can J Microbiol 2009;55(7):874-878.

23. Grossi SG, Genco RJ. Periodontal disease and diabetes mellitus: a two-way relationship. Ann Periodontol 1998;3(1):51-61. 
24. Offenbacher S, Katz V, Fertik G, Collins J, Boyd D, Maynor G, McKaig R, Beck J. Periodontal infection as a possible risk factor for preterm low birth weight. J Periodontol 1996;67(10 suppl):1103-1113.

25. Feingold KR, Soued M, Serio MK, Moser AH, Dinarello CA, Grunfeld C. Multiple cytokines stimulate hepatic lipid synthesis in vivo. Endocrinology 1989;125(1):267-274.

26. Ponchietti A, Erre GL, Fenu P. Effect of TNF-alpha blockers on sperm count and motility in patients with rheumatic diseases: a cross-sectional study. Ann Rheum Dis 2009;68:229.

27. Perdichizzi A, Nicoletti F, La Vignera S, Barone N, D'Agata R, Vicari E, Calogero AE. Effects of tumour necrosis factor-alpha on human sperm motility and apoptosis. J Clin Immunol 2007 Mar;27(2):152-162.

28. Lachter J, Babich JP, Brookman JC, Eliakim R. Resolution of male infertility following anti-tumor necrosis factor (Infliximab): a case report. Int J Gastroenterology 2004;3(1).
29. Nwhator SO. Periodontal disease in smokers, a study of factory workers in Lagos State. Submitted to the National Postgraduate Medical College of Nigeria.

30. Celik O, Kutlu O, Tekcan M, Celik-Ozenci C, Koksal IT. Role of TNF-related apoptosis-inducing ligand (TRAIL) in the pathogenesis of varicocele-induced testicular dysfunction. Asian J Androl 2013;15(2):269-274.

31. Fardini Y, Wang X, Témoin S, Nithianantham S, Lee D, Shoham M, Han YW. Fusobacterium nucleatum adhesin Fad A binds vascular endothelial cadherin and alters endothelial integrity. Mol Microbiol 2011;82(6):1468-1480.

32. Prabha V, Sandhu R, Kaur S, Kaur K, Sarwal A, Mavuduru RS, Singh SK. Mechanism of sperm immobilization by Escherichia coli. Adv Urol 2010. p. 1-6. Article ID 240268.

33. Paulson JD, Polakoski KL. Isolation of a spermatozoal immobilization factor from Escherichia coli filtrates. Fertil Steril 1977; 28(2):182-185. 